\title{
BMJ Open A critical appraisal of clinical trials conducted and subsequent drug approvals in India and South Africa
}

\author{
Dnyanesh Limaye, Janka Marisa Langer, Tjorben Rühling, Gerhard Fortwengel
}

To cite: Limaye D,

Langer JM, Rühling T, et al. A critical appraisal of clinical trials conducted and subsequent drug approvals in India and South Africa. BMJ Open 2015;5:e007304. doi:10.1136/bmjopen-2014007304

- Prepublication history for this paper is available online. To view these files please visit the journal online (http://dx.doi.org/10.1136/ bmjopen-2014-007304).

Received 27 November 2014 Revised 1 April 2015 Accepted 11 May 2015

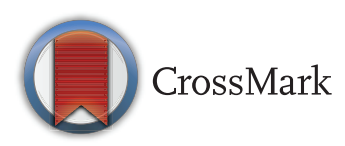

Faculty III, Hochschule Hannover, Hannover, Germany

Correspondence to Dr Dnyanesh Limaye; dnyanesh1in@gmail.com

\section{ABSTRACT}

Objectives: To assess the relation between the number of clinical trials conducted and respective new drug approvals in India and South Africa.

Design: Construction and analysis of a comprehensive database of completed randomised controlled clinical trials based on clinicaltrials.gov from 1 January 2005 to 31 December 2010 and drug approval data from 2006 until 2013 for India and South Africa.

Setting: USA, the EU, India and South Africa.

Main outcome measures: Percentage of completed randomised clinical trials for an Investigational Medicinal Product (IMP) leading to new drug approval in India and South Africa.

Results: A total of 622 eligible randomised controlled trials were identified as per search criteria for India and South Africa. Clustering them for the same sponsor and the same Investigational New Drug (IND) resulted in 453 eligible trials, that is, 224 for India and 229 for South Africa. The distribution of the market application approvals between the EU/USA as well as India and South Africa revealed that out of clinical trials with the participation of test centres in India and/or South Africa, $39.6 \%$ (India) clinical trials and $60.1 \%$ (South Africa) clinical trials led to market authorisation in the EU/USA without a New Drug Application (NDA) approval in India or South Africa.

Conclusions: Despite an increase in clinical trial activities, there is a clear gap between the number of trials conducted and market availability of these new drugs in India and South Africa. Drug regulatory authorities, investigators, institutional review boards and patient groups should direct their efforts to ensuring availability of new drugs in the market that have been tested and researched on their population.

\section{INTRODUCTION}

The drugs we use to treat any conditionfrom an innocuous cough to a lifethreatening cancer-are the outcome of painstaking human clinical trials. These trials are the only way to credibly determine the safety and efficacy of drugs. Without trials, there is no way pharmaceutical research can advance to improve disease management and the very quality of life. Clinical trials are considered as a gold standard in the field of

\section{Strengths and limitations of this study}

- We only selected clinical trials conducted from 1st of January to 31st December 2010 for this study.

- http://www.clinicaltrials.gov was the only source for selection of clinical trials this study.

- We might have missed other websites as source to identify registered clinical trials.

evidence-based medicine. ${ }^{1}$ In recent years, there has been a clear shift in clinical trial sites from core developed countries like the USA and European countries to developing countries like India, China and South American countries. ${ }^{2}$ This shift is related to challenges and opportunities like costs of trials, recruitment issues and regulatory challenges in developed versus developing countries. $^{3-5}$ Since the early 1990s, the growth in the number of people participating in and required for pharmaceutical clinical trials has been massive. The number of clinical trial investigators conducting multinational clinical trials (trials conducted in more than one country with the same protocol) in lowincome settings increased 16-fold in the past decade. ${ }^{3}$ Many of these new trials are being performed in geographical areas of political and economic instability and unprecedented healthcare crises and where subjects are readily accessible. Drug companies' apparent ease of accessibility to such areas has raised questions about the unequal social contexts in which research is being performed and about how conditions of inequality are at present facilitating a global proliferation of pharmaceutical drug trials. This increase brings with it social, legal and ethical implications, and among them are the major issue of how the benefits of this research are shared. $^{2}{ }^{67}$ Our university contact partners from developing countries-India and South Africa-had shown interest in this research question as randomised controlled trials 
conducted in India and South Africa have not been comprehensively assessed, and there is no effort to determine whether this research has led to the availability of new drugs to the local population. We also feel this research question will benefit the clinical research environment in the respective countries. We therefore constructed a comprehensive database of randomised controlled trials in India and South Africa from 2005 to 2010 and evaluated whether this research has resulted in market approvals of new drugs.

\section{METHODS}

\section{Eligibility criteria}

We screened all multinational randomised controlled trials from http://www.clinicaltrials.gov conducted in the period from 1 January 2005 to 31 December 2010. Multinational trials that had trial sites in India and South Africa were selected for this study.

\section{Identification of trials and new drug approvals}

We searched the US trials registry of the National Institutes of Health, ClinicalTrials.gov, the main global trial registration site to identify clinical trials conducted by global sponsors in preselected developing countries, India and South Africa. We only selected the trials which were interventional, phase II and III, funded by industry, registered, conducted and completed between 1 January 2005 and 31 December 2010, as some of the trials might be registered or conducted but may not be completed in the predecided time frame for this research question. After clinical trial completion, the sponsor has to submit the clinical study report within 12 months to the regulatory authorities. On this basis, we decided that 14 months was an adequate period for the sponsor to file a New Drug Application (NDA) in the relevant country. Therefore, we excluded the clinical trials having update information later than 14 month after completion date. We searched http://www.fda.gov US Food and Drug Administration, http://www.ema.europa.eu European Medicines Agency, http://www.cdsco.nic.in Central Drug Standard Control Organization, India (CDSCO) and http://www.mccza.com Medicines Control Council (MCC), South Africa along with South African Medicine Price Registry http://www.mpr.gov.za for new drug approval in the USA, the EU, India and South Africa, respectively, for the time period from 2006 until 2013.

\section{Database}

From each trial, we extracted the following information: title of the trial, sponsor, indication and IMP (Investigational Medicinal Product). From the new product approval database, we extracted the new product approval date. We reviewed the selected sets of trials for a duplicate check on the sponsor, IMP and indication to avoid miscounting the total number of trials potentially being included in the New Drug Approval list. Figure 1 gives the details of generation of data. Search was repeated by us to validate the correctness of data.

\section{Analysis}

Data analysis was done on the following determined data sets by the following criteria: not approved in any of the countries/regions; approved in the EU and/or the USA, but not in India and South Africa, respectively; approved in India/South Africa, respectively, and in either the EU and/or the USA.

\section{RESULTS}

Figure 1 illustrates the initial generation of data and its subsequent handling for analysis. We screened 1175 trials from http://www.clinicaltrials.gov registered in the period from 1 January 2005 to 31 December 2010. Out of 1175 trials, there were 596 and 579 trials for India and South Africa, respectively. Trials with update information later than 14-month after the completion date were eliminated, which resulted in 320 and 302 trials for India and South Africa, respectively. Further clustering clinical trials with the same sponsor and same IND resulted in 224 and 229 clinical trials for India and South Africa, respectively. This formed the basis for our

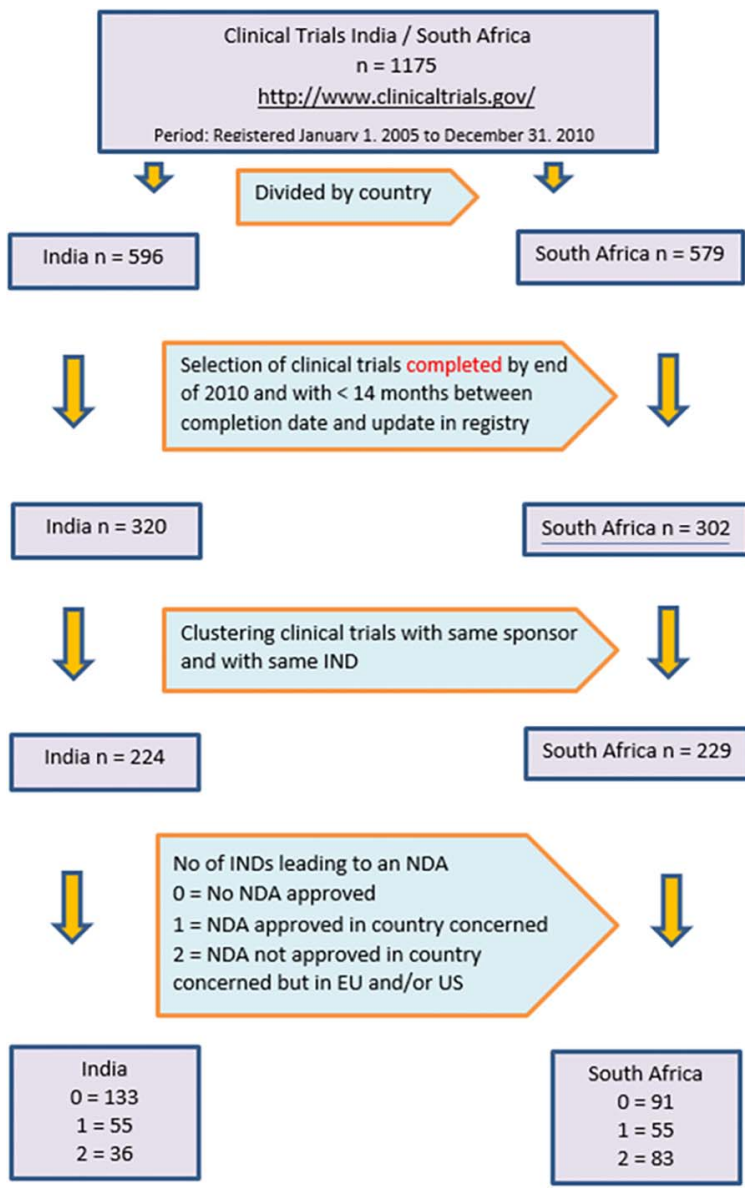

Figure 1 Clinical trials and NDA approvals in India and South Africa. NDA, New Drug Application. 


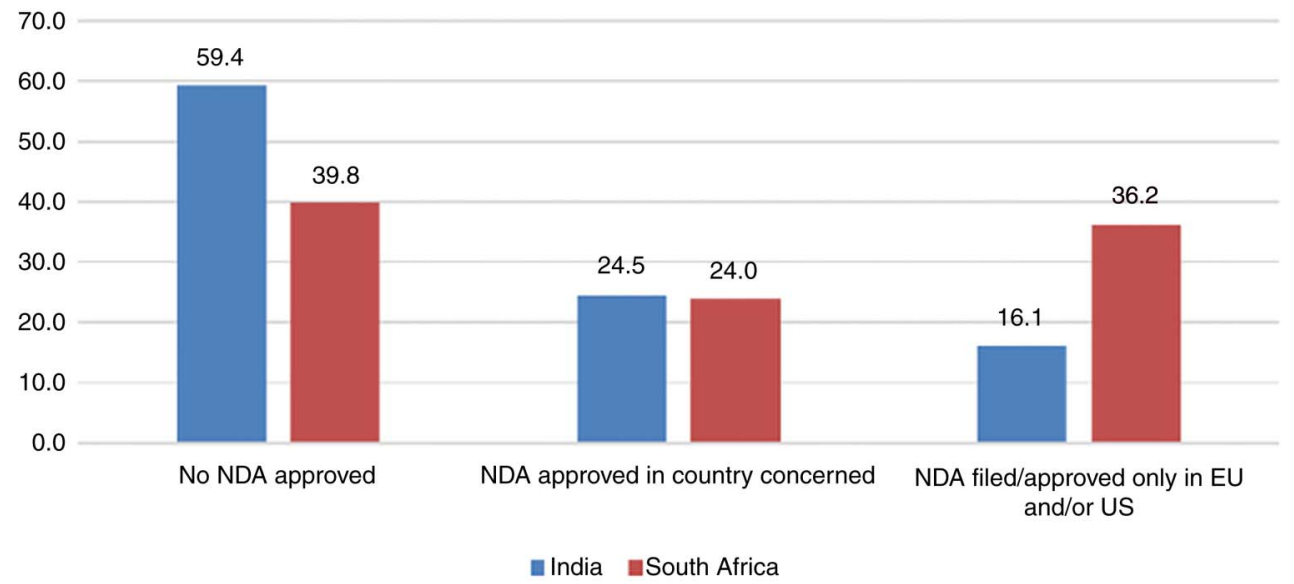

Figure 2 Percentage of clinical trials leading to market approval.

analysis. These clinical trials were screened at the Indian regulatory site (http://www.cdsco.nic.in), South African regulatory sites (http://www.mccza.com and http:// www.mpr.gov.za), European Medicines Agency site (http://www.ema.europa.eu) and USFDA site (http:// www.fda.gov) to determine the new drug approval status in respective countries.

Figure 2 shows the percentage of clinical trials leading to market approval. $59.4 \%$ (India) and $39.8 \%$ (South Africa) of the multinational clinical trials did not result in NDA approval anywhere - not in the respective country (India/South Africa) or the EU/USA. It was seen that only $24.5 \%$ and $24 \%$ clinical trials led to marketing approval in India and South Africa, respectively. It was seen that in $16.1 \%$ approval was only available in the EU and/or the USA without parallel approval in India. In case of South Africa, this number was strikingly high, that is, $36.2 \%$ trials led to approval in the EU and/ or the USA without parallel approval in South Africa.

Inequalities were more evident when we focused on the distribution of marketing approval between the EU/ USA and India/South Africa as seen in figure 3. In 39.6\% and $60.1 \%$ trials, respectively, for India and South Africa, marketing approval was only received in the EU/USA without approval in India and South Africa, respectively.
Table 1 shows the $\%$ of clinical trials and \% cause specific mortality as per the WHO report ${ }^{8}$ for India and South Africa. There were a large number of clinical trials for neuropsychiatric conditions (20\%), diabetes $(19 \%)$ and cardiovascular diseases $(16 \%)$ conducted in India. Diabetes and cardiovascular diseases are listed in the WHO Report as relevant causes for mortality in India with a subsequent country programme to address those diseases. ${ }^{8}$ For clinical trials conducted in South Africa, neuropsychiatric conditions (22\%) and various types of malignancies $(14.5 \%)$, followed by cardiovascular diseases $(12.0 \%)$, were the main indications.

\section{DISCUSSION}

We identified clinical trials conducted from 1 January 2005 to 31 December 2010 and registered on http:// www.clinicaltrials.gov. Our results reveal that there is a mismatch between the percentage of clinical trials conducted and NDAs in India and South Africa. Globally, a large number of multinational clinical trials $(59.4 \%$ in India and $39.8 \%$ in South Africa) did not result in NDA approval anywhere, that is, in the respective countryIndia/South Africa or the EU/USA. This is alarming and highlights the problem with clinical success rate
Figure 3 Distribution of marketing approval between the EU/USA and India/South Africa.

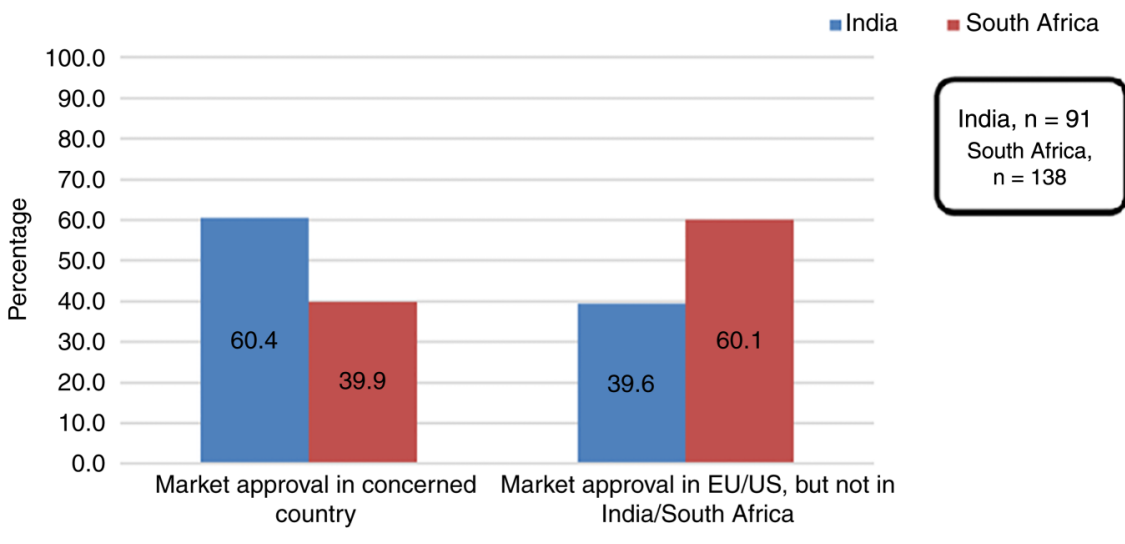


Table 1 Percentage of clinical trials and \% cause specific mortality for India and South Africa

\begin{tabular}{|c|c|c|c|c|}
\hline \multirow[b]{2}{*}{ Diseases } & \multicolumn{2}{|l|}{ India } & \multicolumn{2}{|l|}{ South Africa } \\
\hline & Clinical trials \% & $\begin{array}{l}\text { Cause specific } \\
\text { mortality } \%\end{array}$ & Clinical trials \% & $\begin{array}{l}\text { Cause specific } \\
\text { mortality \% }\end{array}$ \\
\hline Musculoskeletal diseases & 4 & 1.7 & 5 & 1 \\
\hline Neoplasm & 13 & 3.5 & 14.5 & 3.2 \\
\hline Neuropsychiatric conditions & 20 & 11.6 & 22 & 5.9 \\
\hline Cardiovascular diseases & 16 & 12.6 & 12 & 7.7 \\
\hline Diabetes & 19 & 11.0 & 15.7 & 1.8 \\
\hline Eye diseases & 3 & 5.4 & 1.4 & 3.7 \\
\hline Digestive diseases & 3 & 3 & 8.7 & 2 \\
\hline Infectious and parasitic diseases & 13 & 17 & 9.1 & 48 \\
\hline Genitourinary diseases & 5 & 1.1 & 4.5 & 1 \\
\hline Respiratory diseases & 4 & 4.5 & 7.1 & 3 \\
\hline
\end{tabular}

(movement of drug from clinical trials to the market) ${ }^{9}$ This is associated with many factors like trial costs, regulatory framework, trial complexity and patient recruitment issues. Against this background, emerging economies have shown the potential to become global players in the field of clinical research.

After focusing only on the percentage of clinical trials resulting in an NDA, it was clear that for $39.6 \%$ and $60.1 \%$ trials, respectively, for India and South Africa, marketing approval was only received in the EU/USA without approval in India and South Africa. As regards participation in the eventual benefits, the Declaration of Helsinki offers clear guidance, especially for research conducted in the developing countries. ${ }^{10}$ The year 2000 version of the Declaration of Helsinki states categorically that at the end of any research study, every subject entered in the project should be assured of the best proven prophylactic, diagnostic and therapeutic methods identified by that study. ${ }^{10}$ The World Medical Assembly emphasises that medical research is only justified if there is a reasonable likelihood that the populations in which the research is carried out stand to benefit from the results of the research. ${ }^{10}$ The Indian drug regulatory authorities ask sponsors to confirm that they will market the drug after conducting the trial on the Indian population. ${ }^{11}$ However, the result of our study clearly shows that this regulation is not followed by sponsors even after they make a commitment on paper with the regulatory authorities of India.

Also, it is very important to have a balance between the research areas and the present need of the respective countries. ${ }^{4} 12$ Our results show the imbalance between the focused research areas and the disease prevalence of India and South Africa. Similar results have also been reported by Glickman EW that global players are not focusing their research on the priorities of the developing countries. ${ }^{2}$ A comparison between the cause specific mortality of India and South Africa and the indications of clinical trials conducted revealed only a partial match. There were no clinical trials in the area of maternal and perinatal conditions, nutritional disorders which are the main causes of mortality in India. We would also like to focus on the high number of trials conducted in the areas of neoplasms, neuropsychiatry, musculoskeletal diseases and genitourinary diseases which might not be relevant to the local population in India. For South Africa, the WHO report ${ }^{8}$ confirms cardiovascular diseases and neoplasms as critical areas in healthcare. However, infectious diseases and, in particular, HIV form by far the area associated with the highest medical need, which are a far less explored indication for clinical trials conducted in South Africa. Even for South Africa there were a high number of clinical trials in the area of neuropsychiatry, musculoskeletal diseases, diabetes and genitourinary diseases which might not be relevant as per the WHO cause specific mortality data to the local population. This highlights the need to refocus on the issue of vulnerability of emerging economies' patient participation in the clinical trial in spite of discussions over the past decade. ${ }^{41314}$

\section{Implications for Ethics Committees and investigators}

The National Bioethics Advisory Commission (NBAC) ${ }^{14}$ in its report recommends that researchers should, before initiation of a research study, endeavour to secure access for all participants to effective treatment after the trial and that the lack of any such arrangements should be justified to a research ethics committee (REC). The report also recommends that researchers should indicate in their proposals how they intend to make the intervention available to participants after the trial if the intervention is proven successful. There is a need to ensure that developing countries are not used as sites for research that is not of relevance to them and thus protect the vulnerable population. ${ }^{4}$ The Council for International Organizations of the Medical Sciences Guidelines specifically state that all research that is conducted in developing countries and sponsored by developed countries should be of relevance to the developing countries. The relevance of the study to the country is a sure way of ensuring that countries stand to benefit once their citizens participate as subjects in clinical research. In the words of Lang and Siribaddana, "the globalisation of trials should not be about running inexpensive 
trial sites to benefit distant people, but should focus on bringing research to populations who have previously been under-represented in clinical trials and enabling these same communities the benefits from new drugs."

Research Ethics Committees, being the gatekeepers when it comes to health research, have to play an important role of ensuring that the communities and individuals are not exploited in research. ${ }^{12}$ More often, it is very difficult for a community to voice its concerns due to various reasons including lack of appropriate structures for communication. The ethics committees can therefore serve as the voice of the voiceless communities and individuals in developing countries. The developing countries and institutions need to come to the negotiating table with sponsors since they have a very useful resource in research-human beings who are willing to participate in research. The benefit sharing ensures that the disadvantaged at least benefit in some way from an activity in which they have participated.

\section{Implications for regulators}

The pace of clinical research in developing countries is accelerating in India and South Africa. Both these countries are not in a stage to support independent clinical research like western developed countries. They need to be a part of international clinical trials, but this should be without compromising ethics and research benefits sharing. Regulatory authorities from India and South Africa should formulate a regulation making it compulsory to market the new drugs at affordable prices in India and South Africa after conducting clinical trials on the local population. It is very important that clinical research should focus on the most relevant disease of these countries. There should be a provision to blacklist or fine the sponsor if they do not market the new drugs in India or South Africa and market only in the EU/USA.

\section{CONCLUSION}

In this paper, we take the view that clinical research is important for developing countries as it offers benefits in terms of knowledge, patient care and business. Sponsors should not exploit the local population for research without offering the benefits of research by making the new drug available in markets of developing countries. Sponsors and investigators should take reasonable efforts, plan before study initiation and discuss with benefits and risk of study with local communities. Clinical research stands on the basic premise of enhancing the present scientific knowledge and, if ethically designed and conducted, it is the most scientific path to invent new treatment modalities. Therefore, the benefits of this ethical research should be extended post trial not only to study subjects but to the entire host community.

In general, the goal of clinical research is to support the drug development and availability of new medicines while ensuring that research is always balanced to the local need of the country. There is a need not only to have stringent regulations, but also to monitor its follow-up. We feel that institutional review boards, investigators and patient groups, along with regulatory authorities, have a clear role in ensuring market availability of drugs after research and thus bridging the gap between the developing and developed nations.

Contributors DL has contributed to this manuscript by: developing and deciding the research project; data analysis and interpretation; medical writing and revisions as suggested by BMJ Open; final approval for release; responsible for all the accuracy and assuring all the questions related to this manuscript will be answered and resolved. GF has contributed by: developing the research project; data analysis and interpretation; medical writing; final approval for release from our side; in agreement to be responsible for answering questions and issues for this manuscript. JML has contributed by: data search and acquisition; medical writing drafts of manuscript; responsible for final release; in agreement to be responsible for answering questions and issues for this manuscript. TR has contributed by: data collection and acquisition; medical writing for manuscript; responsible for final release; in agreement to be responsible for answering questions and issues for this manuscript.

Competing interests None declared.

Provenance and peer review Not commissioned; externally peer reviewed.

Data sharing statement Additional data can be accessed via the Dryad data repository at http://datadryad.org/ with the doi:10.5061/dryad.013hq.

Open Access This is an Open Access article distributed in accordance with the Creative Commons Attribution Non Commercial (CC BY-NC 4.0) license, which permits others to distribute, remix, adapt, build upon this work noncommercially, and license their derivative works on different terms, provided the original work is properly cited and the use is non-commercial. See: http:// creativecommons.org/licenses/by-nc/4.0/

\section{REFERENCES}

1. Yadav $P$, Jaykaran, Chaudhari $M$, et al. Clinical trials registered in clinical trial registry of India: a survey. J Pharmacol Pharmacother 2011;2:289-92.

2. Glickman SW, McHutchison JG, Peterson ED, et al. Ethical and scientific implications of the globalization of clinical research. $N$ Engl J Med 2009;360:816-23.

3. Petryna A. Ethical variability: drug development and globalizing clinical trials. Am Ethnologist 2005:183-97.

4. Lang T, Siribaddana S. Clinical trials have gone global: Is this a good thing? PLoS Med 2012;9:e1001228.

5. Karlberg JPE. Globalization of sponsored clinical trials. Nat Rev Drug Discov 2008;7.458.

6. Solomon RB. Distributive justice and clinical trials in the third world Theor Med Bioeth 2001;22:169-76.

7. Thiers FA, Sinskey AJ, Berndt ER. Trends in the globalization of clinical trials. Nat Rev Drug Discov 2008;7:13-14.

8. World Health Organization: Global Health Observatory, Country Statistics. 2010. http://www.who.int/gho/countries/en/

9. DiMasi JA, Feldman L, Seckler A, et al. Trends in risks associated with new drug development: success rates for investigational drugs. Clin Pharmacol Ther 2010;87:272-7.

10. Ethical Principles for Medical Research Involving Human Subjects. World Medical Association Declaration of Helsinki. 2000.

11. Requirements for filing of application to market new chemical entities. India: Central Drugs Standard Control Organization, 2014.

12. The ethical implications of the global outsourcing of clinical research Health Lett 2013;29:5-6.

13. Denny CC, Christine Grady C. Clinical research with economically disadvantaged populations. J Med Ethics 2007;33:382-5.

14. Chapter 4. When research is concluded-access to the benefits of research by participants, communities, and countries. In: Ethical and policy issues in international research: clinical trials in developing countries. VA, USA: National Bioethics Advisory Commission, 2001:144-198. 